\title{
Screening of five marine-derived fungal strains for their potential to produce oxidases with laccase activities suitable for biotechnological applications
}

Wissal Ben Ali $^{1,2^{*}}$ De, Delphine Chaduli i, ${ }^{2,3}$, David Navarro ${ }^{2,3}$, Christian Lechat ${ }^{4}$, Annick Turbé-Doan ${ }^{2}$, Emmanuel Bertrand ${ }^{2}$, Craig B. Faulds², Giuliano Sciara², Laurence Lesage-Meessen ${ }^{2}$, Eric Record ${ }^{2}$ and Tahar Mechichi ${ }^{1}$

\begin{abstract}
Background: Environmental pollution is one of the major problems that the world is facing today. Several approaches have been taken, from physical and chemical methods to biotechnological strategies (e.g. the use of oxidoreductases). Oxidative enzymes from microorganisms offer eco-friendly, cost-effective processes amenable to biotechnological applications, such as in industrial dye decolorization. The aim of this study was to screen marinederived fungal strains isolated from three coastal areas in Tunisia to identify laccase-like activities, and to produce and characterize active cell-free supernatants of interest for dye decolorization.

Results: Following the screening of 20 fungal strains isolated from the harbors of Sfax and Monastir (Tunisia), five strains were identified that displayed laccase-like activities. Molecular-based taxonomic approaches identified these strains as belonging to the species Trichoderma asperellum, Stemphylium lucomagnoense and Aspergillus nidulans. Among these five isolates, one T. asperellum strain (T. asperellum 1) gave the highest level of secreted oxidative activities, and so was chosen for further studies. Optimization of the growth medium for liquid cultures was first undertaken to improve the level of laccase-like activity in culture supernatants. Finally, the culture supernatant of $T$. asperellum 1 decolorized different synthetic dyes belonging to diverse dye families, in the presence or absence of 1hydroxybenzotriazole (HBT) as a mediator.
\end{abstract}

Conclusions: The optimal growth conditions to produce laccase-like active cell-free supernatants from T. asperellum 1 were $1.8 \mathrm{mM} \mathrm{CuSO}_{4}$ as an inducer, $1 \% \mathrm{NaCl}$ to mimic a seawater environment and $3 \%$ sucrose as a carbon source. The culture supernatant of T. asperellum 1 effectively decolorized different synthetic dyes belonging to diverse chemical classes, and the presence of HBT as a mediator improved the decolorization process.

Keywords: Marine-derived fungi, Trichoderma asperellum, Laccase-like activity, Laccase, Dyes

* Correspondence: wissal.BEN-ALI@etu.univ-amu.fr

${ }^{1}$ Ecole Nationale d'Ingénieurs de Sfax, Laboratoire de Biochimie et de Génie enzymatique des lipases, Université de Sfax, Sfax, Tunisie

${ }^{2}$ Biodiversité et Biotechnologie Fongiques, Aix-Marseille Université, INRA UMR1163, Marseille, France

Full list of author information is available at the end of the article

C The Author(s). 2020 Open Access This article is licensed under a Creative Commons Attribution 4.0 International License, which permits use, sharing, adaptation, distribution and reproduction in any medium or format, as long as you give appropriate credit to the original author(s) and the source, provide a link to the Creative Commons licence, and indicate if changes were made. The images or other third party material in this article are included in the article's Creative Commons licence, unless indicated otherwise in a credit line to the material. If material is not included in the article's Creative Commons licence and your intended use is not permitted by statutory regulation or exceeds the permitted use, you will need to obtain permission directly from the copyright holder. To view a copy of this licence, visit http://creativecommons.org/licenses/by/4.0/ The Creative Commons Public Domain Dedication waiver (http://creativecommons.org/publicdomain/zero/1.0/) applies to the data made available in this article, unless otherwise stated in a credit line to the data. 


\section{Background}

Water pollution is a serious environmental issue. Many industries are reported to dump wastes into rivers, lakes, ponds and streams to hide them from Environmental Protection Agencies [1]. Many studies have thus focused on microbial enzyme transformation and detoxification of pollutants [2,3]. For this purpose, fungi are considered more robust than bacteria and are generally more tolerant to high concentrations of pollutants [4]. They produce high levels of extracellular enzymes with large industrial potential in eco-friendly, cost-effective processes [4].

Most fungi studied today are isolated from forests and other terrestrial environments. Few studies have explored marine fungal diversity [5]. Yet marine environments are extremely complex and host a broad spectrum of fungal species [6]. Although some novel fungal genera have been identified in marine environments and characterized, most marine-derived fungi seem to be related to terrestrial fungi, such as Fusarium sp., Aspergillus sp. and Penicillium sp. Marine-derived fungi have been shown to be present in various habitats, such as coastal areas, marine sediments and deep sea, associated with sponges, microalgae, fish and mangrove wood. Marine fungi have been classified as either obligate or facultative: obligate marine fungi grow exclusively in a marine habitat, whereas facultative marine fungi are of freshwater or terrestrial origin but are able to thrive in marine environments [7-9]. "The term marine-derived fungi is often used because most fungi isolated from marine samples are not demonstrably classified as obligate or facultative marine microorganisms" as described by Osterhage [10]. Recently, an online database was created to obtain more insight into the taxonomy of marine-derived fungi (www.marinefungi.org), with a full description of all known marine fungal species [11]. The utility of discovering the biodiversity of marine-derived fungi is not merely taxonomic: within each marine habitat, local microbial communities have adapted to seawater environmental conditions, and their enzymes are therefore potentially very attractive for biotechnology applications, owing to their properties, including thermostability, and salt and $\mathrm{pH}$ tolerance. Given their adaption to low temperature, high salinity, high pressure and oligotrophic conditions typical of the marine environment, marine-derived fungi are clearly a promising source of novel bioactive metabolites not found in terrestrial strains of the same species, including enzymes and laccases [9].

The laccases (EC 1.10.3.2) are a multigenic family of multicopper oxidases distributed across bacteria, fungi and plants. They catalyze, at a mononuclear copper center T1, the one-electron oxidation of four substrate molecules including substituted phenols, arylamines and aromatic thiols, to the corresponding radicals, with the simultaneous reduction at a trinuclear copper center T2/T3 of molecular oxygen to water [12]. The laccases form a large group of oxidoreductases, with a broad spectrum of substrates [12]. With their active copper cluster, they do not need any heterogeneously added cofactors for their activity, and their co-substrate, oxygen, is usually present in their environment. Most of these enzymes are naturally secreted and so are generally highly stable in the extracellular environment. The high level of inducible expression of laccase-encoding genes in most fungal species adds to their attractiveness in biotechnological applications [3]. New sources of laccases with special properties, such as high-redox potential, high salt and temperature tolerance, or cold adaptivity, are wanted for industrial applications. A broad variety of fungal strains isolated from several sea grasses, algae and decaying wood samples are able to produce laccases [13]. Mabrouk et al. [14] have isolated Trematosphaeria mangrovei from a mangrove ecosystem, which produces a laccase in significant quantities. A thermostable, metal-tolerant laccase is produced by the marine-derived fungus Cerrena unicolor [15]. Several researchers have isolated laccase-producing fungi from different sources, notably among the species Trichoderma harzianum, Trichoderma atroviride, Trichoderma longibrachiatum, Trametes versicolor, Lentinus tigrinus, Trametes pubescens, Cyathus bulleri, Paecilomyces sp., Phanerochaete chrysosporium, Lentines edodes, Pleurotus ostreatus, Ganoderma lucidum, Alternaria tenuissima and Trichoderma sp. [13]. Because fungi from marine environments have adapted to grow under high saline (15-34 ppt (parts per thousand)) and alkaline conditions, the laccases they produce are of potential interest for the bioremediation of high-salt and alkaline effluents, such as those from the pulp and paper, tanning and textile industries [16].

Reports on the identification of marine-derived laccases are still scant. The main purpose of this study was to isolate and identify new marine-derived fungal strains, to screen them for their capacity to produce laccaseactive cell-free supernatants, and to determine, for a few selected strains, the optimal growth conditions for obtaining high levels of laccase-like activities.

\section{Results}

Isolation and identification of fungal strains

Marine-derived fungi from various marine areas of the Tunisian coast were isolated and screened. Twenty fungal strains were isolated up to the stage of monomorphic cultures in solid medium. Five of them showed positive oxidative activity on both DMP and ABTS added as substrates to solid medium in Petri dishes. 
Cultures of the pure isolates were run for molecular analysis with primers directed against the DNA sequences of the ITS region. Phylogenetic trees based on ITS sequences were constructed to find the relationships of the newly isolated strains to previously characterized species (Figs. 1 and 2). As shown in Fig. 1, phylogenetic analysis using ITS-derived sequences shows that our isolate, Stemphylium sp., clustered closely with Stemphylium vesicarium and $S$. lucomagnoense. In order to affiliate our isolate to one of these strains, morphological traits of the fungus were determined. After 3 weeks on MEA at $25^{\circ} \mathrm{C}$, colony reached $4-5 \mathrm{~cm}$ diameter. The white aerial mycelium became pale olivaceous grey at margin, producing flexuous, unbranched, smooth, hyaline to pale yellowish brown conidiophores (28-)35$85 \times 3-4 \mu \mathrm{m}$, with conidiogenous cells enlarged at apex, pale brownish, 5-7 $\mu \mathrm{m}$ wide (Fig. 1). Conidia are solitary, ellipsoid, dark brown, and verrucose $(22-30 \times 12-$ $16 \mu \mathrm{m})$, with $(1-2-) 3$ transverse septa and $1(-2)$ longitudinal septa. As the morphological features correspond to those described by Woudenberg et al. [18], we affiliated this isolate to S. lucomagnoense. Based on phylogenetic analysis, we affiliated our second isolate to $A$. nidulans (Fig. 2). The sequences obtained were deposited at Genbank under accession numbers MK691703 and MK691704 for S. lucomagnoense and A. nidulans respectively. Three other strains were affiliated to the genus Trichoderma based on sequences of the TEF- $1 \alpha$ region (Fig. 3). The three isolates clustered in a clade comprising exclusively 23 Trichoderma species, with high bootstrap values for each branch (Fig. 3). The related sequences, corresponding to strains Trichoderma sp. 1, Trichoderma sp. 2 and Trichoderma sp. 3 were deposited under accession numbers MK966034, MK966035 and MK966036, respectively. It can be inferred from the phylogenetic tree that the strain closest to isolates Trichoderma sp. 1, Trichoderma sp. 2 and Trichoderma sp. 3 is the species Trichoderma asperellum.

\section{Production of fungal culture supernatants with laccase- like activity}

Laccase-like activities of the five selected isolates were studied starting from liquid cultures. First we confirmed that the activity was not related to heme-containing peroxidase activities by adding either $\mathrm{H}_{2} \mathrm{O}_{2}$ or catalase to the reaction assay. Under these two conditions, no change in the activity was observed, suggesting that the activity is therefore not related to peroxidases $\left(\mathrm{H}_{2} \mathrm{O}_{2}\right.$ dependent oxidases) but most probably correlated to laccases. Marked laccase-like activities were measured with T. asperellum 1, 2 and 3. A. nidulans and S. lucomagnoense produced lower activity levels. The highest laccase-like activities were detected with $T$. asperellum 1 and 2, with $185 \mathrm{U} \mathrm{L}^{-1}$ (Fig. 4a). Laccase-like activities increased during the first $48 \mathrm{~h}$ and then reached a plateau. Because the five selected strains were isolated from marine environments, we assumed they were biologically adapted to living in saline conditions. We therefore tested whether the levels of secreted laccase-like activities were affected by adding $1 \% \mathrm{NaCl}$ to the culture media (Fig. 4b). T. asperellum 1 yielded the highest level of laccase-like activities $\left(193 \mathrm{UL}^{-1}\right)$. For the three $T$. asperellum strains, secreted laccase-like activity sharply

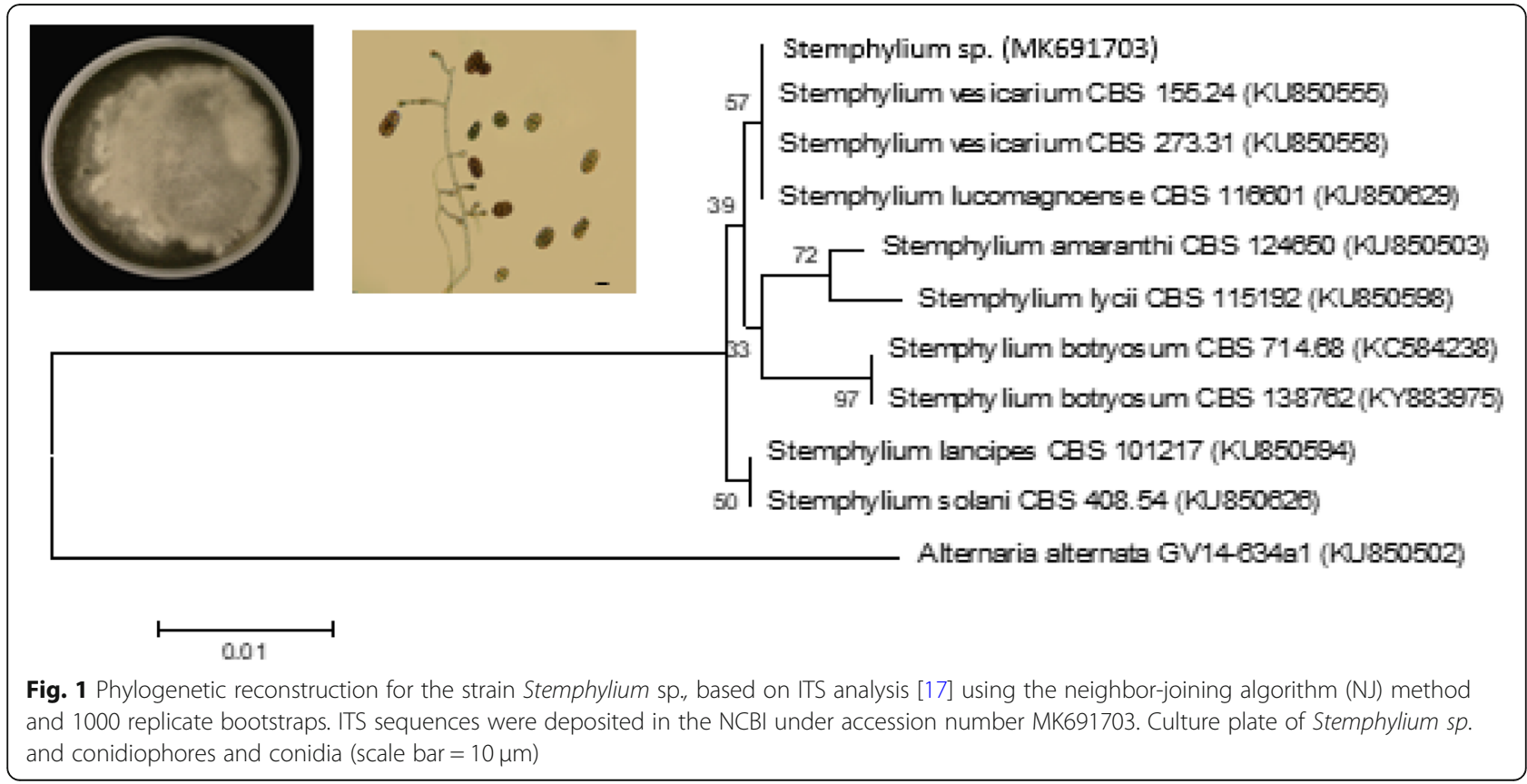




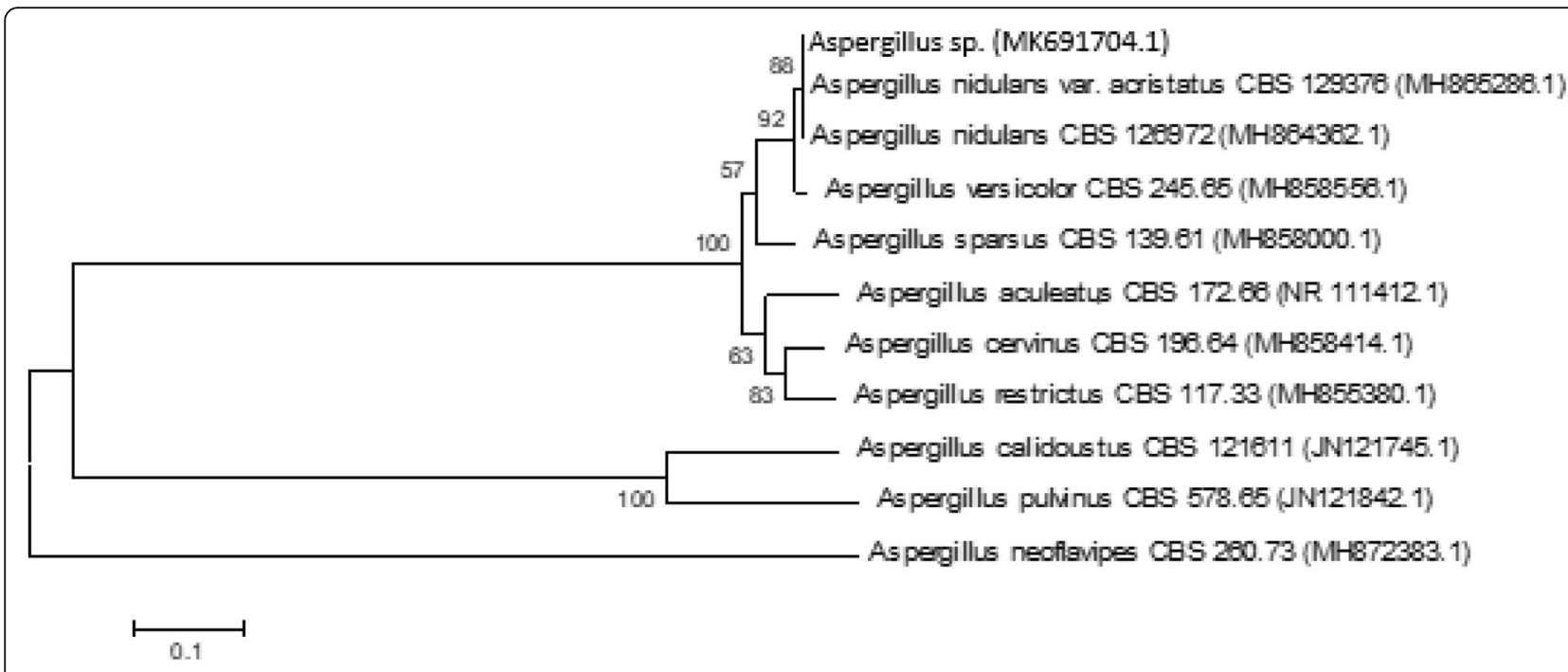

Fig. 2 Phylogenetic reconstruction for the strain Aspergillus sp, based on ITS analysis using the neighbor-joining algorithm (NJ) method and 1000 replicate bootstraps, ITS sequences were deposited in the NCBI under accession number MK691704

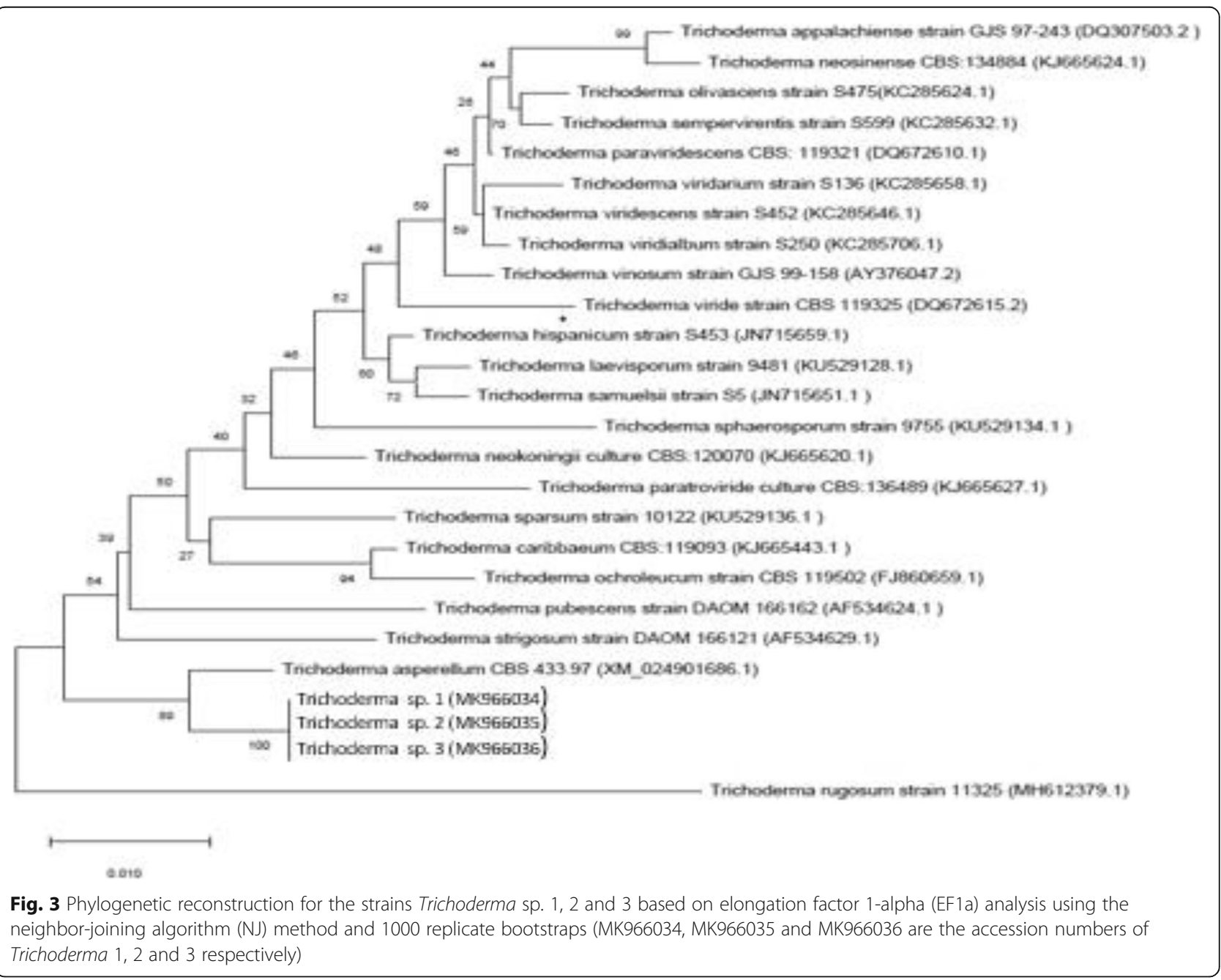




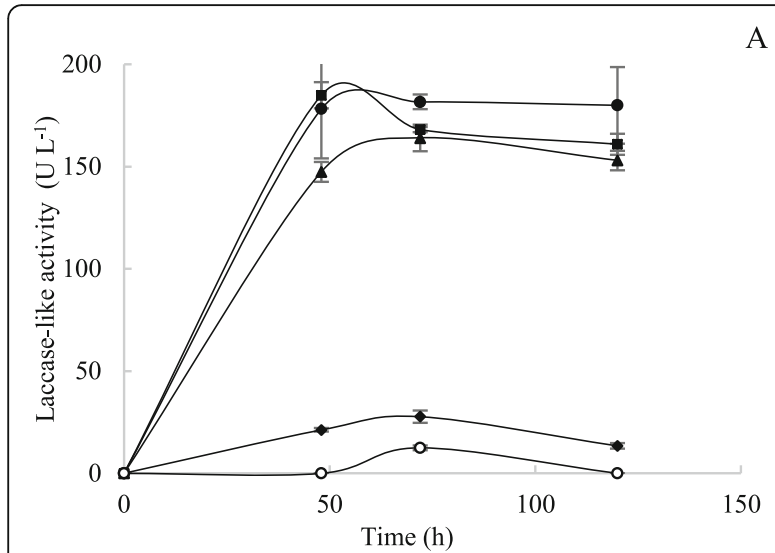

A

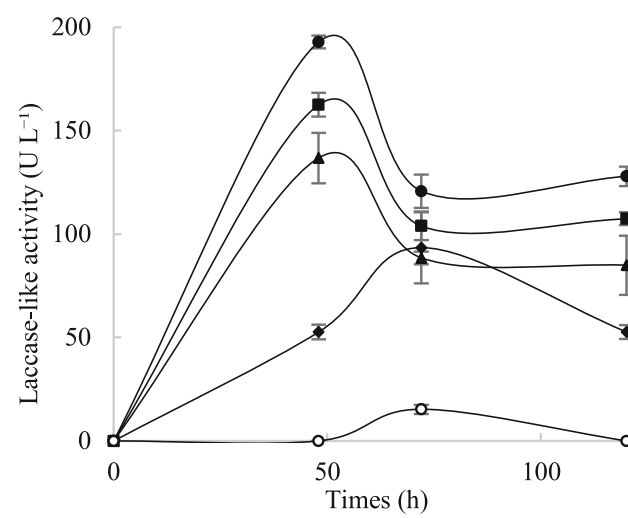

Fig. 4 a Laccase activity of Trichoderma asperellum 1 (•), Trichoderma asperellum 2 ( $\mathbf{\bullet}$ ), Trichoderma asperellum 3 ( $\mathbf{\Delta}$ ), Stemphylium lucomagnoense ( ) and Aspergillus nidulans (o) during 5 days of culture with ABTS as the substrate at pH 5.5 without (a) or with (b) $1 \% \mathrm{NaCl}$. Each data point

(mean $+/$ - standard deviation) is the result of triplicate experiments

decreased after $48 \mathrm{~h}$ to level off at around $120 \mathrm{U} \mathrm{L}^{-1}$, less than in cultures without $\mathrm{NaCl}$, suggesting that the enzymes responsible might be sensitive to $\mathrm{NaCl}$. Interestingly, laccase-like activity was significantly induced by adding $\mathrm{NaCl}$ to $\mathrm{S}$. lucomagnoense cultures, yielding 110 $\mathrm{U} \mathrm{L}^{-1}$ (4-5 times more than the $25 \mathrm{U} \mathrm{L}^{-1}$ obtained without $\mathrm{NaCl}$ ). Because of the high levels of laccase-like activity in its culture supernatant, T. asperellum 1 was chosen for further studies.

Effect of sea salt and different concentrations of $\mathrm{NaCl}$ on laccase-like activities in Trichoderma asperellum 1 cultures Different concentrations of $\mathrm{NaCl}(0,1,2,3,4$ and $5 \% \mathrm{w} /$ v) were added to the medium used for T. asperellum 1 cultures, and laccase-like activity in the resulting supernatant was quantified. The results are shown in Fig. 5a. As previously observed, the addition of $1 \% \mathrm{NaCl}$ induced the production of laccase-like activities, with an optimum of $235 \mathrm{UL}^{-1}$ after 3 days of fungal culture. Laccase-like activity instead decreased at higher concentrations of $\mathrm{NaCl}$. Natural seawater does not contain only sodium chloride, but also large quantities of chlorides and sulfates of calcium, potassium, and magnesium, and much lower amounts of many trace elements. Addition of $1 \%$ sea salt to $T$. asperellum 1 cultures was therefore also tested (Fig. 5b). In these conditions, no real effect on laccase-like activity was found, with a $160 \mathrm{U} \mathrm{L}^{-1}$ maximum at Day 4, against $170 \mathrm{UL}^{-1}$ at Day 3 with no $\mathrm{NaCl}$. Interestingly however, with sea salt, laccase-like activity did not decrease after $72 \mathrm{~h}$, remaining stable up to $200 \mathrm{~h}$ growth.

\section{Influence of $\mathrm{CuSO}_{4}$ and of different carbon sources on laccase-like activity in Trichoderma asperellum 1}

To study the effect of $\mathrm{CuSO}_{4}$ on secreted laccase-like activity, different concentrations of $\mathrm{CuSO}_{4} \quad(800 \mu \mathrm{M}$,
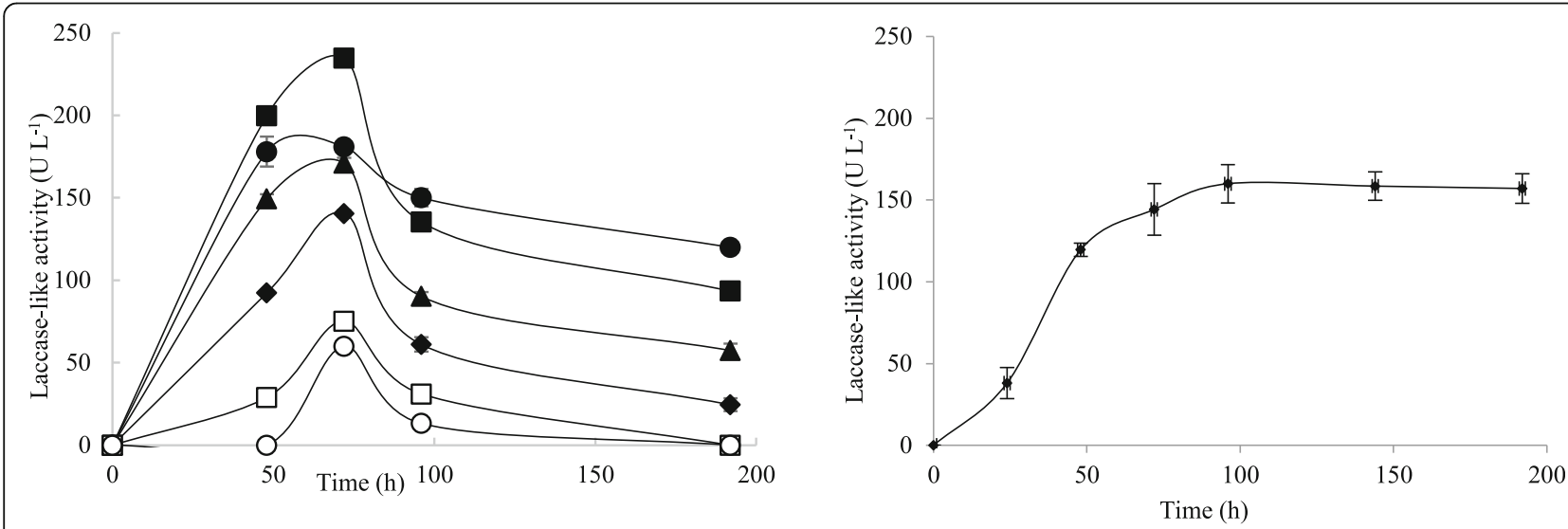

Fig. 5 a Effect of different concentrations of $\mathrm{NaCl}(0 \%(\bullet), 1 \%(\boldsymbol{\bullet}), 2 \%(\mathbf{\Delta}), 3 \%(\bullet), 4 \%(\square)$ and 5\% (०)) on Trichoderma asperellum 1 laccase-like activity. $\mathbf{b}$ Effect of $1 \%$ of sea salt on T. asperellum 1 laccase-like activity. Each data point (mean $+/-$ standard deviation) is the result of triplicate experiments 
$1000 \mu \mathrm{M}, 1800 \mu \mathrm{M}$ and $2000 \mu \mathrm{M})$ were added to the $\mathrm{M} 7$ medium used for $T$. asperellum 1 cultures. The results reported in Fig. 6 indicate that laccase-like activity increased significantly in the supernatant when cultures were supplemented with $\mathrm{CuSO}_{4}$. These increments were dose-dependent and significantly higher at around $2000 \mu \mathrm{M} \mathrm{CuSO}_{4}$, as clearly visible at $72 \mathrm{~h}$, when activity $\left(170 \mathrm{UL}^{-1}\right)$ was more than 3 times higher than in cultures without $\mathrm{CuSO}_{4}\left(50 \mathrm{U} \mathrm{L}^{-1}\right)$.

Carbon sources are also known to strongly affect the levels of secreted fungal laccase-like activities. Accordingly, we tested the effect of adding $3 \%$ of sucrose, glucose or starch to the M7 production medium (Fig. S1 Supplementary data). We found that 3\% sucrose resulted in higher levels of laccase-like activity $\left(270 \mathrm{UL}^{-1}\right)$ in the resulting supernatant.

\section{Decolorization of synthetic dyes}

T. asperellum 1 cell-free supernatant was prepared in the optimized production medium (M7 containing 1\% $\mathrm{NaCl}, \quad 3 \%$ sucrose and $\left.1.8 \mathrm{mM} \quad \mathrm{CuSO}_{4}\right)$. The decolorization ability of the culture supernatant was tested on five different dyes, belonging to three different dye families (reactive, azo and anthraquinone). The culture supernatant was incubated in the presence of five dyes $\left(50 \mu \mathrm{g} \mathrm{mL}^{-1}\right.$ each), namely Remazol Brilliant Blue $\mathrm{R}$ (RBBR), Reactive Black 5 (RB5), Direct Red 75 (DR75), Acid Orange 51 (AO51) and Turquoise Blue (TB) for 48 h. Results showed that the presence of HBT, as observed for most laccases, improved the decolorization process, probably by facilitating electron transfer between oxidative enzymes from the culture supernatant and the substrate dye molecules. Figure 7 shows that in all cases HBT improved the decolorization efficiency of the $T$. asperellum 1 culture supernatant, but only with RB5 was it necessary. RB5 was barely decolorized with no

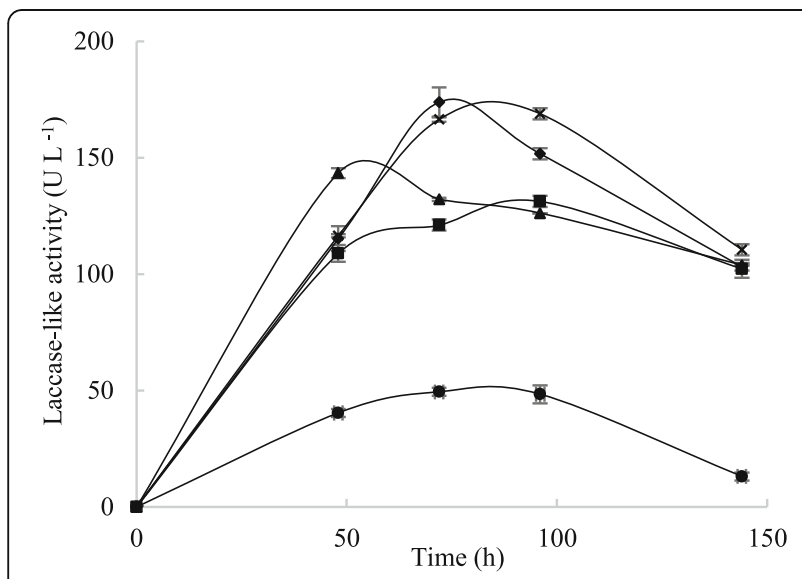

Fig. 6 Effect of different concentrations of $\mathrm{CuSO}_{4}(0 \mathrm{mM}(\bullet), 0.8 \mathrm{mM}$ $(\boldsymbol{\bullet}), 1 \mathrm{mM}(\boldsymbol{\Delta}), 1.8 \mathrm{mM}(\bullet)$ and $2 \mathrm{mM}(\mathbf{)})$ on Trichoderma asperellum 1 laccase-like activity mediator (only 9\% decolorization), whereas in $24 \mathrm{~h}$ after addition of HBT the decolorization increased from 9 to 90\%. With RBBR, DR75 and TB, the decolorization increased with the use of HBT from 60 to $80 \%$, while for AO51 only $5 \%$ of additional decolorization was achieved (from 75 to $80 \%$ ). Finally, our study shows that as observed for laccases, the addition of HBT enhances decolorization to different extents depending on the dye to be oxidized.

\section{Discussion}

Fungi are recognized for their ability to produce a broad variety of extra-cellular enzymes [19]. However, most fungi studied to date have been isolated from forests and other terrestrial environments, and very few studies have explored marine fungal diversity. A large proportion of the diversity of marine-derived fungi may have originated from their terrestrial counterparts, with the appearance of strains able to live in harsh marine environments (high pressure, low temperature, oligotrophic nutrients, high salinity, etc.) [20, 21]. These specific conditions account for the significant differences between the enzymes generated by marine-derived microorganisms and their homologs from terrestrial counterparts [22]. Finally, marine-derived microorganisms have been studied to exploit their potential to generate new natural products and to degrade plant biomass [23].

In this study, 20 marine-derived fungi were isolated from Tunisian marine biotopes. Five of them were selected for their oxidative profile on DMP and ABTS. These five strains were identified as ascomycetes belonging to the species Aspergillus nidulans, Stemphylium lucomagnoense and Trichoderma asperellum (three strains belonging to the latter species). Among these marine-derived strains, Aspergillus nidulans, an anamorph of Emericella nidulans, is an important model ascomycete for eukaryotic genetics. A few studies have been dedicated to marine-derived $A$. nidulans species, such as two relatively recent ones reporting on the production of molecules of interest: melanin precursors with UVB protective properties [24] and antitumor alkaloids [25]. Another strain identified in this study belongs to the phylum ascomycetes (Dothideomycetes, Pleosporales, Pleosporaceae), specifically to the Stemphylium genus, that encompasses worldwide-distributed saprophytes and plant pathogens affecting a variety of agricultural crops. Molecular analysis branched Stemphylium sp. with both S. vesicarium and Stemphylium lucomagnoense in the phylogenetic tree, but morphological traits confirmed that the isolated species is S. lucomagnoense, an anamorph of Pleospora lucomagnoense. To date, only two studies have focused on marine-derived Pleospora. The first deals with the production of antimicrobial 

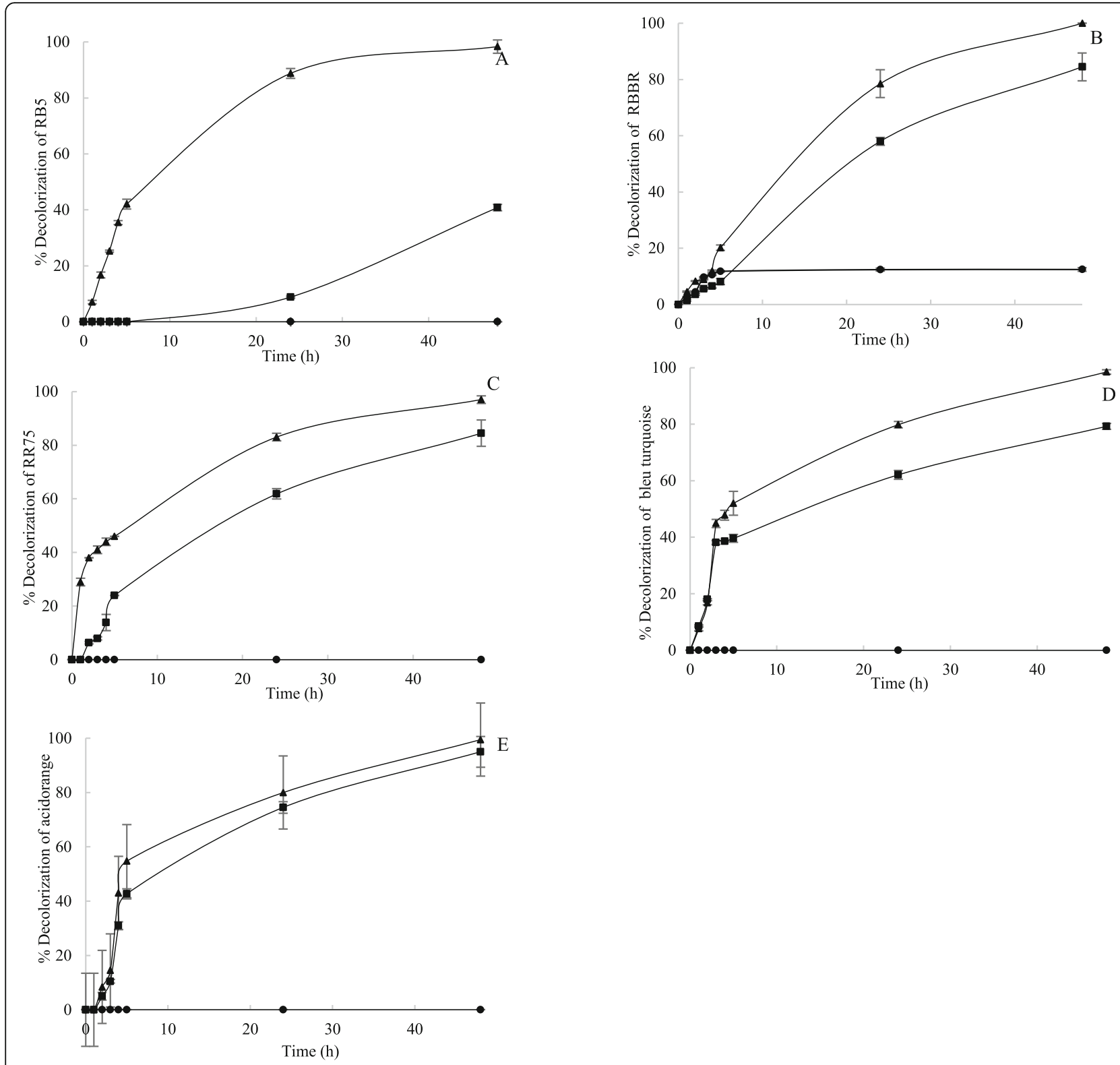

Fig. 7 Decolorization of the five reactive dyes (50 $\mathrm{mg} \mathrm{L}^{-1}$ each), namely industry Reactive Black 5 (RB5) (a), Remazol Brilliant Blue R (RBBR) (b), RR75 (c), Blue Turquoise (d) and Acid Orange (E) in $48 \mathrm{~h}$ (\% of decolorization in the presence of 1-hydroxybenzotriazole (HBT) (•), \% of decolorization in the presence of enzyme ( $\mathbf{-})$ and \% of decolorization in the presence of enzyme and HBT $(\mathbf{\Delta}))$. The disappearance of the color by Trichoderma asperellum 1 culture supernatant was monitored at specific wavelengths (585, 597, 520, 438 and $606 \mathrm{~nm})$ with time (1, 2, 3, 4, 5, 24 and $48 \mathrm{~h}$ ). Each data point (mean $+/$ - standard deviation) is the result of duplicate experiments

compounds [26] and the second with the phylogeny of Pleospora gaudefroyi [27].

A number of molecular markers have successfully been used for the taxonomic identification of fungal genera and species, and the ITS rDNA region has often been considered a marker of choice for the fungal kingdom [28]. However, sequencing of the TEF- $1 \alpha$ region is considered a sensitive tool for identification in mycology, with better resolution than ITS, e.g. when studying the genus Trichoderma [29]. In this study, TEF- $1 \alpha$ sequence-based phylogeny suggests that the species phylogenetically closest to our three isolates Trichoderma sp. 1, 2 and 3 is Trichoderma asperellum, a fungus naturally found in soils [30]. Although Trichoderma species are usually found in terrestrial habitats, some isolates have been collected from marine environments, where they live in association with algae [31] and sponges [32], in coastal sediments [33], or as endophytes in mangroves [34]. Among these marine-derived species we found T. asperellum, which was further studied for 
its production of secondary metabolites, such as sesquiterpenes [35] and antibacterial peptides [36].

Different Trichoderma species have been extensively studied as sources of cellulases, but also oxidases such as laccases [37]. This was the case, for instance, with the terrestrial species Trichoderma reesei [37], T. harzianum and T. longibrachiatum [38], and for the marine-derived Trichoderma sp. [39]. A terrestrial T. asperellum producing oxidases including laccases was applied to degrade polycyclic aromatic hydrocarbons in soil [40]. In our study, the culture supernatant of five fungal isolates showed different amounts of laccase-like activities in liquid cultures and under saline conditions. The highest laccase-like activity was observed with the strain $T$. asperellum 1 , in cultures with or without $1 \% \mathrm{NaCl}$. For comparison, while marine-derived A. sclerotiorum produced $9.26 \mathrm{U} \mathrm{L}^{-1}$ laccase-like activity after 7 days culture in $3 \%(\mathrm{w} / \mathrm{v}) \mathrm{NaCl}$, T. asperellum 1 produced about 190 $\mathrm{U} \mathrm{L}^{-1}$. In another study [41], optimization of laccase-like activity levels from Trichoderma sp. grown in $0.5 \% \mathrm{NaCl}$ yielded approximately $2000 \mathrm{UL}^{-1}$, but activity was assayed using $o$-tolidine instead of ABTS as a substrate, so that these results are not directly comparable with ours. The finding of laccase-like activities from fungal cultures grown in $\mathrm{NaCl}$-containing media could be of benefit to industrial and biotechnological processes in which salinity is high [42]. In our study, we show that high levels of salt-tolerant laccase-like activity can be found using synthetic dyes as substrates. These findings open the way to the discovery of novel biocatalysts for the textile industry, whose effluents contain not only dyes, but also high salt concentrations. Secretome and enzyme characterization will be the next step in our research.

To maximize the levels of laccase-like activity in $T$. asperellum 1 cultures, we evaluated the effect of different concentrations of $\mathrm{NaCl}$ and known inducers, such as $\mathrm{CuSO}_{4}$ and three carbon sources. These parameters can affect the productivity of various oxidases secreted in the culture medium, owing to an inhibition of fungal growth or to effects on enzyme stability and activity, possibly in relation to protein surface charges and perturbation of global or local protein folding [43]. In our study, higher levels of laccase-like secreted activity were found when $1 \% \mathrm{NaCl}$ was added to $T$. asperellum 1 cultures. Above this concentration, activity gradually decreased with increasing $\mathrm{NaCl}$ concentration. The effect of $\mathrm{NaCl}$ was also studied for other marine fungi such as Cerrena unicolor isolated from mangroves [44], and was shown to enhance laccase activity in fungal culture supernatants. Similarly, by adding sea salt to T. asperellum 1 cultures, we obtained an increase in the supernatant oxidase activity in time, with a maximum at $75 \mathrm{~h}$ (like with $\mathrm{NaCl}$ ), but no decrease afterwards (unlike with $\mathrm{NaCl}$ ). In previous studies we demonstrated the activation by sea salt of two laccases from the mangrove fungus Pestalotiopsis sp. [45], while a laccase from Trematosphaeria mangrovei lost $50 \%$ of its activity in $1 \% \mathrm{NaCl}$ [14]. Saltadapted enzymes are generally characterized by highly negative surface charges that are assumed to contribute to protein stability in extreme osmolytic conditions [46]. Copper has been reported to be a strong laccase inducer in several fungal species [47, 48]. It has been also reported that the increase in activity is proportional to the amount of copper added [49]. In our study, optimal $\mathrm{CuSO}_{4}$ concentration was $1.8 \mathrm{mM}$ for $T$. asperellum 1 cultures, yielding about $173 \mathrm{UL}^{-1}$ laccase-like activity. These results are in agreement with previous ones [50], showing optimum laccase activity $\left(32.7 \mathrm{U} \mathrm{mL}^{-1}\right)$ in Pestalotiopsis sp. cultures with $2.0 \mathrm{mM} \mathrm{CuSO}_{4}$, and decreased activity above this concentration. Nakade et al. [51] reported that the best $\mathrm{CuSO}_{4}$ concentration for laccase production in Polyporus brumalis was $0.25 \mathrm{mM}$. $\mathrm{CuSO}_{4}$ induction of laccase is related to the active site architecture of these enzymes, which generally contain four copper atoms per polypeptide. Copper addition to the culture medium was also reported to induce laccase gene transcription [52]. In addition, it has been reported that copper can be toxic, as it interacts with nucleic acids, proteins, enzymes and metabolites associated with major cell functions, so that $\mathrm{CuSO}_{4}$ concentration should be checked case by case [52]. Several studies have proved that the choice of carbon sources affects the production of ligninolytic enzymes [53]. The purpose of glucose supplementation to lignocellulose for fungal cultures is twofold. First, it promotes the growth and rapid establishment of the fungus within the solid raw material. Second, the fungus needs an additional, easily metabolizable carbon source to sustain lignin degradation from lignocellulosic substrates [54]. In our study, sucrose was the best substrate for secreted laccase-like activity from $T$. asperellum 1 cultures $\left(290 \mathrm{UL}^{-1}\right)$, as previously shown for Arthrospira maxima [55].

Industrial dyes are usually of synthetic origin and have complex aromatic structures that make them highly resilient and more difficult to biodegrade [56]. Reactive dyes, for example, contain chromophore groups such as azo or anthraquinone. Most of these dyes are not toxic themselves, but after release into aquatic environments may be converted into potentially carcinogenic amines that impact the ecosystem downstream of the mill [57]. Currently employed physical and chemical methods have been shown to have some serious limitations, such as high cost, high salt content utilization, and problems related to the disposal of concentrate $[58,59]$. In this regard, emphasis has been placed on developing biological processes, because they are more effective than more conventional, physical and chemical methods [57]. The 
production of oxidases with laccases from marinederived ascomycetes, zygomycetes and basidiomycetes has been under-researched [42, 60]. Similarly, to our knowledge, only one study reports on the application of laccase-active supernatants from a marine Trichoderma to degrade synthetic dyes [41], one describes the production of laccase from marine-derived Aspergillus sclerotiorum [60] and no work is available on laccases derived from Stemphylium species. In this study, the dye decolorization ability of $T$. asperellum 1 culture supernatant was tested against five different industrial synthetic dyes: Reactive Black 5 (RB5), Remazol Brilliant Blue R (RBBR), Direct Red 75 (DR75), Turquoise Blue (TB) and Acid Orange 51 (AO51). These dyes belong to different dye families: reactive, azo and anthraquinone. It is generally observed that the extent of decolorization depends on the enzyme properties (and so the biological source) together with the chemical properties, structure and size of the dye molecule $[2,61]$. Owing to their high molecular weight, for example, sulfonated azo dyes are unable to pass through the cell membrane, and degradation of these dyes must therefore take place extracellularly. The role of redox mediators in azo bond detoxification has also already been shown [62]. For instance, it has been reported that adding the mediator HBT to the laccase-active culture supernatant of Paraconiothyrium variabile enhances the decolorization of RB5, RBBR, DR75 and TB [63].

In a previous study we investigated RBBR decolorization by the culture filtrate of the terrestrial ascomycete Trametes trogii and by a laccase isolated from it [64]. The purified laccase decolorized up to $97 \%$ of a $100 \mathrm{mg} \mathrm{L}^{-1}$ dye solution, with only $0.2 \mathrm{U} \mathrm{mL}^{-1}$ enzyme. In our test conditions, we reached comparable results (60-80\% decolorization) with $T$. asperellum 1 culture supernatant, with or without HBT. In general, different marine-derived strains will degrade RBBR to different extents, for example Flavodon flavis degraded RBBR by more than 90\% [65], but Cerrena unicolor only by $46 \%$ [66].

Biodegradation of RB5 was investigated using the culture supernatant of the Trichoderma atroviride F03 yielding 91.1\% decolorization without mediators [67]. Three products of this biodegradation reaction $(1,2,4$ trimethyl benzene, 2, 4-ditert butylphenol and benzoic acid-TMS derivatives) were identified, confirming the validity of enzymatic treatment without generating aromatic amines, which are highly toxic [67]. In comparison, the $T$. asperellum 1 culture supernatant achieved only $10 \%$ of RB5 decolorization without HBT, and up to $80 \%$ in the presence of the mediator.

AO51 is a water-soluble anionic azo dye. Typically containing one to three sulfonic groups, it is widely applied to color wool, silk and polyamide. The nature and level of toxicity of AO51 has not yet been well established [68], but sulfonated azo dyes (including naphthalene sulfonic acids, naphthols, naphthoic acids, benzidines, etc.), and particularly benzidines are a focus of attention because of their carcinogenicity [68]. AO51 degradation by crude laccase from Trametes trogii grown in solid cultures on sawdust has been investigated [68], and above $88 \%$ decolorization in the presence of HBT was achieved. Our results show that by contrast, with $T$. asperellum 1 culture supernatant, HBT was not essential for AO51 decolorization. To our knowledge, this is the first report of AO51 decolorization with no need for laccase mediators.

To date, only a few studies have dealt with decolorization of the phthallocinine dye TB. Plácido et al. showed that Leptosphaerulina sp. effectively decolorized TB and two real effluents from textile industries [69]. This decolorization was catalyzed by the production of significant quantities of laccase $\left(650 \mathrm{U} \mathrm{L}^{-1}\right)$ and manganese peroxidase $\left(100 \mathrm{U} \mathrm{L}^{-1}\right)$. Leptosphaerulina sp. enzymatic extracts exhibited decolorizing activity when ABTS was added as a mediator. Similarly, the culture supernatant of $T$. asperellum 1 showed maximum $\mathrm{TB}$ biodegradation capacity when HBT was added.

Remarkably high levels of DR75 degradation (95$100 \%)$ were achieved after $120 \mathrm{~h}$ incubation with Penicillium oxalicaum culture supernatant [70]. In that study, high levels of manganese peroxidase activity $(659.4 \pm 20$ $\mathrm{UL}^{-1}$ ) were measured in the culture supernatant of $P$. oxalicaum, indicating the involvement of heme peroxidases in the decolorization process. By contrast, in our study no peroxidase activity was detected in the culture supernatant of $T$. asperellum 1, suggesting for the first time to our knowledge that oxidase-catalyzed DR75 degradation takes place instead.

Further studies will be needed to gain further insight into the enzymatic mechanisms deployed by marinederived fungi to cope with their environment. It will be necessary to identify the key enzymes secreted by $T$. asperellum 1 growing in saline conditions, and to produce and characterize them, with a focus on saltdependency and the structure-function relationship underlying enzyme properties. To assess the potential of the culture supernatant of T. asperellum 1 or enzymes for enzymatic bioremediation of textile effluents, the degradation products of enzymatically treated model dyes and industrial samples need to be precisely identified and characterized, and their impact on human health and environment determined.

\section{Conclusion}

In this work, we collected several fungal samples from the harbour of Sfax, Tunisia. After a purification procedure, the molecular and morphological identification of 
these samples showed that the isolate fungal strains correspond to Trichoderma asperellum, Stemphylium lucomagnoense and Aspergillus nidulans. Analyzing their oxidase activities $T$. asperellum strain ( $T$. asperellum 1 ) gave the highest level of secreted oxidative activities. Therefore, this study showed that the optimal growth conditions to produce laccase-like active cell-free supernatants from $T$. asperellum 1 were $1.8 \mathrm{mM} \mathrm{CuSO}_{4}$ as an inducer, $1 \% \mathrm{NaCl}$ to mimic a seawater environment and $3 \%$ sucrose as a carbon source and the culture supernatant of this strain effectively decolorized different synthetic dyes belonging to diverse chemical classes, and the presence of HBT as a mediator improved the decolorization process.

\section{Methods}

\section{Sample collection}

The environmental samples (woods immersed in seawater, seaweeds, marine plants, pieces of nets) used in this study were collected from four different Tunisian marine biotopes: the fishing port, the Sidi Mansour and the Casino sites at Sfax, and the polluted Khnis site at Monastir. These sites were chosen because of their pollution, with the intention of isolating fungal strains resistant to polluted water, and enzymes able to work in the presence of several contaminant species and aromatic compounds. The samples were collected in sterile tubes using a sterile spatula and stored at $4{ }^{\circ} \mathrm{C}$ until use.

\section{Isolation of fungi}

Small pieces of sample were inoculated on $3.9 \%(\mathrm{w} / \mathrm{v})$ potato dextrose agar (PDA) (Sigma-Aldrich, Saint-QuentinFallavier, France) and 1.8\% (w/v) malt extract (Sigma-Aldrich), with $3.4 \%(\mathrm{w} / \mathrm{v}) \mathrm{NaCl}$ and $0.1 \%(\mathrm{w} / \mathrm{v})$ chloramphenicol to prevent bacterial growth, and incubated at $30^{\circ} \mathrm{C}$ for 3 days until fungal growth was observed. Apparently monomorphic cultures obtained after at least two transfers onto fresh agar plates were further authenticated using molecular tools to check strain purity and identity.

\section{Preliminary screening of the isolates}

Preliminary screening for oxidative activity was performed in PDA plates supplemented with $2 \mathrm{mM} 2,6$ dimethoxyphenol (DMP) or $200 \mu \mathrm{M}$ 2,2'-azino-bis-(3ethylbenzthiazoline-6-sulfonic acid) (ABTS) as substrates. The plates were incubated at $30^{\circ} \mathrm{C}$ for 3 days and the presence of orange and purple halos around the mycelium was considered as the positive sign of substrate oxidation.

\section{Molecular identification (DNA extraction, PCR and sequencing)}

The mycelium of selected strains was obtained by liquid culture in $50 \mathrm{~mL}$ flasks in malt extract medium for 3 days. Genomic DNA was isolated from 40 to $80 \mathrm{mg}$ of mycelium powder using a GeneJET Genomic DNA Purification Kit (Thermo Scientific, Waltham, USA) following the manufacturer's instruction. DNA concentration was estimated at $260 \mathrm{~nm}$ using a Nanodrop 2000 instrument (Thermo Fisher Scientific, Wilmington, USA).

The extracted DNA was used as the template in a PCR to amplify the partial sequences of two DNA loci, namely the internal transcribed spacer region (ITS) and the translation elongation factor $1 \alpha$ region (TEF-1 $\alpha$ ). The primers used for the amplification were ITS5 (5' - GGAAGTAAAAGTCG TAACAAGG-3') and ITS4 (5'-TCCT-CCGCTTATTG ATATGC-3') [71] for the former (used for the Aspergillus and Stemphylium isolates), and TEF1 $\alpha-983-\mathrm{F}-\mathrm{CF} 2$ (5'GCYCCYGGHCAYCGTGAYTTYAT- $3^{\prime}$ ) and TEF1 $\alpha$ 2218-R-CR2 (5'-ATGACACCRACRGCRACRGTYTG-3') [29] for the latter (used for the Trichoderma strains). PCR was performed using a Expand High Fidelity Kit (Roche Diagnostics $\mathrm{GmbH}$, Mannheim, Germany) in $5 \mu \mathrm{L}$ buffer $(100 \mathrm{mM}$ Tris $\mathrm{HCl}, 150 \mathrm{mM} \mathrm{MgCl} 2$ and $500 \mathrm{mM} \mathrm{KCl}$ ) with $1.5 \mathrm{mM} \mathrm{MgCl}_{2}, 0.25 \mu \mathrm{M}$ of each primer, $1 \mu \mathrm{L}$ of deoxynucleoside triphosphate $(200 \mu \mathrm{M}$ of each dNTP), $1 \mu \mathrm{L}$ of DNA (about $100 \mathrm{ng}$ ), and Taq DNA polymerase $(25 \mathrm{mU}$. $\mu \mathrm{L}^{-1}$ ), in a final volume of $50 \mu \mathrm{L}$. Cycling parameters were $94{ }^{\circ} \mathrm{C}$ for 2 min followed by 40 cycles of $94{ }^{\circ} \mathrm{C}$ for $15 \mathrm{~s}, 51{ }^{\circ} \mathrm{C}$ for $30 \mathrm{~s}$, and $72{ }^{\circ} \mathrm{C}$ for $1 \mathrm{~min}$, with a final extension at $72^{\circ} \mathrm{C}$ for $10 \mathrm{~min}$. Negative control reactions lacking template DNA were performed in parallel. Amplified fragments were visualized on $1 \%$ agarose gels (FlashGel ${ }^{\mathrm{m}}$ System) and sequenced using the two PCR primers (Roche Diagnostics GmbH, Mannheim, Germany).

To deduce the phylogeny of the fungal isolates, the sequences ITS and TEF- $1 \alpha$ were compared with data available at the public database Genbank by using the BLASTn sequence match algorithm [71]. The best hits for each species retrieved from the BLAST search were retained and used to construct phylogenetic trees. Sequences were aligned using the CLUSTAL W program [72], and phylogenetic and molecular evolutionary analyses were performed using MEGA X [73]. The phylogenetic tree was constructed using the neighbor-joining algorithm [74] with bootstrap values calculated from 1000 replicates [60].

The fungal strains were deposited at the Spanish type culture collection (CECT) under the reference numbers CECT 21166, CECT 21167 and CECT 21168 for Trichoderma asperellum 1, 2 and 3 respectively, CECT 21164 for Stemphylium lucomagnoense and CECT 21165 for Aspergillus nidulans.

\section{Fungal cultures}

For solid late culture, S. lucomagnoense was grown on MEA ( $30 \mathrm{~g}$ of malt extract with $20 \mathrm{~g}$ of agar). For other fungal cultures, elected marine fungal strains were 
grown in submerged cultures in $50 \mathrm{~mL}$ M7 medium, and culture supernatant was used to retrieve ABTS-oxidizing laccase-like activity as previously described [75]. Fifty milliliter of 3-day precultures of fungal mycelia were vortexed using glass beads $(0.6 \mathrm{~mm})$ for $1 \mathrm{~min}$. The homogenized mycelial fragments were used to inoculate $250 \mathrm{~mL}$ Erlenmeyer flasks containing $50 \mathrm{~mL}$ of M7 medium. The medium (M7) contained $\left(\mathrm{g} \mathrm{L}^{-1}\right)$ : glucose 5 , peptone 5 , yeast extract 1 , ammonium tartrate 2, $\mathrm{KH}_{2} \mathrm{PO}_{4} 1, \mathrm{MgSO}_{4} .7 \mathrm{H}_{2} \mathrm{O} 0.5, \mathrm{KCl} 0.5$, trace element solution $1 \mathrm{~mL}$. The trace element solution composition was $\left(\mathrm{g} \mathrm{L}^{-1}\right): \mathrm{B}_{4} \mathrm{O}_{7} \mathrm{Na}_{2} \cdot 10 \mathrm{H}_{2} \mathrm{O} \quad 0.1, \mathrm{CuSO}_{4} \cdot 5 \mathrm{H}_{2} \mathrm{O} \quad 0.01$, $\mathrm{FeSO}_{4} .7 \mathrm{H}_{2} \mathrm{O} \quad 0.05, \quad \mathrm{MnSO}_{4} .7 \mathrm{H}_{2} \mathrm{O} \quad 0.01, \quad \mathrm{ZnSO}_{4} .7 \mathrm{H}_{2} \mathrm{O}$ $0.07,\left(\mathrm{NH}_{4}\right)_{6} \mathrm{Moo}_{7} \mathrm{O}_{24} \cdot 4 \mathrm{H}_{2} \mathrm{O} 0.01$. The final $\mathrm{pH}$ was adjusted to 5.5. The cultures were incubated at $30^{\circ} \mathrm{C}$ and $160 \mathrm{rpm}$, and aliquots were withdrawn daily. $\mathrm{Cu}^{2+}$ induction was performed in M7 medium supplemented with $2 \mathrm{mM} \mathrm{CuSO}_{4}$.

\section{Laccase-like activity assay}

Laccase-like activity was measured by monitoring the oxidation of $5 \mathrm{mM}$ ABTS (Sigma-Aldrich) in $0.1 \mathrm{M}$ citrate phosphate buffer ( $\mathrm{pH} 5)$ at $436 \mathrm{~nm}$ for $1 \mathrm{~min}$ [76]. The reaction mixture $(1 \mathrm{~mL})$ contained $0.1 \mathrm{~mL}$ supernatant of the culture medium, which was centrifuged for $10 \mathrm{~min}$ at $12000 \mathrm{rpm}$. Oxidase activity was determined as the increase in absorbance at $436 \mathrm{~nm}\left[\left(\varepsilon_{436 \mathrm{~nm}}=29,300\right.\right.$ $\mathrm{M}^{-1} \mathrm{~cm}^{-1}$ ) [77]. One unit of ABTS-oxidizing activity is defined as the amount of enzyme needed to oxidize $1 \mu \mathrm{mol}$ of ABTS per minute at room temperature. Measurements were also conducted in the presence of either $\mathrm{H}_{2} \mathrm{O}_{2}(0.5 \mathrm{mM})$ or catalase (280 units per $\mathrm{ml}$ of assay) to confirm that no activity was due to heme-containing peroxidases.

\section{Influence of $\mathrm{NaCl}$, sea salt, $\mathrm{CuSO}_{4}$ and different carbon sources on laccase-like activity}

To compare the effect of $\mathrm{NaCl}$ and sea salt on the production of active cell-free supernatants, standard M7 medium was supplemented with increasing concentrations of either $\mathrm{NaCl}$ or sea salt $(1-5 \% \mathrm{w} / \mathrm{v})$. Fifty milliliter cultures were grown in $250 \mathrm{~mL}$ Erlenmeyer flasks for 7 days at $30^{\circ} \mathrm{C}$, and samples were withdrawn periodically. $\mathrm{CuSO}_{4}$ was also supplemented to cultures as an inducer of laccase-like activity in case laccases were involved. To determine the suitable concentration of $\mathrm{CuSO}_{4}$ for an optimal production of laccase-like activities, the following concentrations of $\mathrm{CuSO}_{4}$ were tested: $800 \mu \mathrm{M}, 1000 \mu \mathrm{M}, 1800 \mu \mathrm{M}$ and $2000 \mu \mathrm{M}$. To find the suitable carbon source for highest laccase-like activity in culture supernatants, the effect of different carbon sources, such as sucrose, glucose and starch was studied. The carbon sources were tested at a concentration of 3\% in M7 production medium. The Erlenmeyer flasks (250
$\mathrm{mL}$ ) containing $50 \mathrm{~mL}$ of the production medium were incubated at $30^{\circ} \mathrm{C}$ for a period of 7 days.

\section{Dye decolorization by the culture supernatant of Trichoderma asperellum 1}

To test the ability of $T$. asperellum 1 cultures to decolorize industrial dyes, five different dyes used in the textile industry were selected: Remazol Brilliant Blue R (RBBR), Reactive Black 5 (RB5), Direct Red 75 (DR75), Acid Orange 51 (AO51) and the Turquoise Blue (TB). Dyes were solubilized in water at a concentration of 500 $\mathrm{mg} \mathrm{L}^{-1}$. Each dye was incubated at $30^{\circ} \mathrm{C}$ in $0.1 \mathrm{M}$ phosphate-citrate buffer $\mathrm{pH} 5.0$ at a final concentration of $50 \mathrm{mg} \mathrm{L}^{-1}$, together with aliquots of culture supernatant accounting for total ABTS-oxidizing activity of $0.6 \mathrm{U} \mathrm{L}^{-1}$, in a final volume of $1 \mathrm{~mL}$. Measurements were conducted in the presence or absence of $1 \mathrm{mM} \mathrm{1-}$ hydroxybenzotriazole (HBT). Color disappearance was monitored at the maximum absorbance wavelength for each dye (585, 597, 520, 438 and $606 \mathrm{~nm}$ for RBBR, RB5, DR75, AO51 and the TB respectively). For each reaction mixture, absorbance was recorded at 1, 2, 3, 4, 5, 24 and $48 \mathrm{~h}$. The percentage decolorization was calculated by taking the maximum absorbance of each untreated dye solution as the control ( $100 \%$ color). Optical density was measured using an Optizen Pop QX UV/Vis spectrophotometer (Klab, King of Prussia, USA). All experiments were performed in triplicate.

Decolorization was defined as the percentage of absorbance loss compared to the control, untreated dye solution (defined as 100\% absorbance, ABSORBANCE $t_{0}$ ), using the formula:

$$
\text { decolorization }(\%)=\frac{(\text { ABSORBANCE } t 0-\text { ABSORBANCE } t \mathrm{f}) \times 100}{\text { ABSORBANCE } t 0 .}
$$

\section{Supplementary information}

Supplementary information accompanies this paper at https://doi.org/10 1186/s12896-020-00617-y.

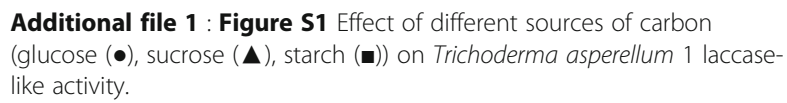

\section{Abbreviations}

HBT: 1-hydroxybenzotriazole; DMP: 2,6-dimethoxyphenol; ABTS: 2,2'-azino-bis(3-ethylbenzthiazoline-6-sulfonic acid); MEA: Malt extract agar; PDA: Potato dextrose agar; ITS: The internal transcribed spacer region; TEF-1a: Translation elongation factor1a region; RBBR: Remazol Brilliant Blue R; RB5: Reactive Black 5; DR75: Direct Red 75; AO51: Acid Orange 51; TB: Turquoise Blue;

CECT: Spanish Type Culture Collection; $\mathrm{H}_{2} \mathrm{O}_{2}$ : Hydrogen peroxide; h: hour

\section{Acknowledgments}

Authors would kindly like to thank Sophie Auzelle, the translation service manager in the center of Metaform Languages (sophie.auzelle@metaformlangues.fr), for editing the English text of a draft of this manuscript.

Permission to collect sample

No permission was necessary to collect samples. 


\section{Authors' contributions}

WBA carried out the fungal collection and isolation, fungal cultures, enzyme tests and dye decolorization. DC and DN performed molecular marker amplification and contributed to fungal identification. CL and LLM managed the phylogenetic and morphological analysis of the fungal strains. ATD contributed to enzyme screening. EB, CBF, GS, TM and ER designed and supervised the experiments, and wrote the manuscript with WBA. All authors read and approved the final version of the manuscript.

\section{Funding}

This work was supported by the PHC-Utique (39274UH 2018-2020, 18G0817) In this study the funder had no role in the data collection, analysis and interpretation, or writing of the manuscript.

\section{Availability of data and materials}

All the data generated and analyzed during this study are included in the published article. The fungal strains were deposited at the Spanish type culture collection (CECT) under the reference numbers CECT 21166, CECT 21167 and CECT 21168 for Trichoderma asperellum 1, 2 and 3 respectively, CECT 21164 for Stemphylium lucomagnoense and CECT 21165 for Aspergillus nidulans.

\section{Ethics approval and consent to participate}

Not applicable

\section{Consent for publication}

Not applicable

\section{Competing interests}

The authors declare they have no conflicts of interest.

\section{Author details}

'Ecole Nationale d'Ingénieurs de Sfax, Laboratoire de Biochimie et de Génie enzymatique des lipases, Université de Sfax, Sfax, Tunisie. ${ }^{2}$ Biodiversité et Biotechnologie Fongiques, Aix-Marseille Université, INRA UMR1163, Marseille, France. ${ }^{3}$ INRA, Aix-Marseille Université, UMR1163, CIRM-CF, Marseille, France. ${ }^{4}$ Ascofrance, 64 route de Chizé, F-79360 Villiers-en-Bois, France.

\section{Received: 27 March 2020 Accepted: 27 April 2020}

\section{Published online: 12 May 2020}

\section{References}

1. Rao MA, Scelza R, Scotti R, Gianfreda L. Role of enzymes in the remediation of polluted environments. J Soil Sci Plant Nutr. 2010;10:333-53.

2. Couto SR. Decolouration of industrial azo dyes by crude laccase from Trametes hirsuta. J Hazard Mater. 2007:148:768-70.

3. Couto SR, Herrera JLT. Laccases in pollution control. Ter Aquat Environ Tox. 2007:1:34-45.

4. Ellouze M, Sayadi S. White-rot fungi and their enzymes as a biotechnological tool for xenobiotic bioremediation. Intech. 2016;17:103-20.

5. Richards TA, Jones MDM, Leonard G, Bass D. Marine fungi: their ecology and molecular diversity. Annu Rev Mar Sci. 2011:4:495-522.

6. Amend A, Burgaud G, Cunliffe M, Edgcomb VP, Ettinger CL, Gutiérrez $M H$, Heitman J, Hom EFY, Laniri G, Jones AC, Kagami M, Picard KT, Quandt CA, Raghukumar S, Riquelme M, Stajich J, Vargas-Muñiz J, Walker A, Yarden O, Gladfelter AS. Fungi in the marine environment: Open questions and unsolved problems. mBio. 2019;10:e01189-18.

7. Kohlmeyer J, Volkmann-Kohlmeyer B. Fungi from coral reefs: a commentary. Mycol Res. 2003:107:386-7.

8. Li Q, Wang G. Diversity of fungal isolates from three Hawaiian marine sponges. Microbiol Res. 2009;164:233-41.

9. Bonugli-Santos RC, Dos Santos Vasconcelos MR, Passarini MRZ, Vieira GAL, Lopes VCP, Mainardi PH, Dos Santos JA, de Azevedo DL, Otero IVR, da Silva Yoshida AM, Feitosa VA, Pessoa A Jr, Sette LD. Marine-derived fungi: diversity of enzymes and biotechnological applications. Front Microbiol. 2015:6:269-84.

10. Osterhage C. Isolation, structure determination and biological activity assessment of secondary metabolites from marine-derived fungi. PhD Thesis university of Carolo-Wilhelmina at Braunschweig; 2001.

11. Jones EBG, Pang K-L, Abdel-Wahab MA, Scholz B, Hyde KD, Boekhout T, Ebel R, Rateb ME, Henderson L, Sakayaroj J, Suetrong S, Dayarathne MC, Kumar V,
Raghukumar S, Sridhar KR, Bahkali AHA, Gleason FH, Norphanphoun C. An online resource for marine fungi. Fungal Divers. 2019;96:347-433.

12. Reiss R, Ihssen J, Richter M, Eichhorn E, Schilling B, Thöny-Meyer L. Laccase versus laccase-like multi-copper oxidase: a comparative study of similar enzymes with diverse substrate spectra. PLoS One. 2013;8:e65633.

13. Kantharaj P, Boobalan B, Sooriamuthu S, Mani R. Lignocellulose degrading enzymes from fungi and their industrial applications. Int J Cur Res Rev. 2017;9:21-33.

14. Atalla MM, Zeinab HK, Eman RH, Amani AY, Abeer AA. Characterization and kinetic properties of the purified Trematosphaeria mangrovei laccase enzyme. Saudi J Biol Sci. 2013;20:373-81.

15. D'Souza-Ticlo D, Sharma D, Raghukumar C. A thermostable metal-tolerant laccase with bioremediation potential from a marine-derived fungus. Mar Biotechnol. 2009;11:725-37.

16. Raghukumar C, D'Souza-Ticlo D, Verma A. Treatment of colored effluents with lignin-degrading enzymes: An emerging role of marine-derived fungi. Crit Rev in Microbiol. 2008:34:189-206.

17. White T, Bruns T, Lee S, Taylor J, Innis M, Gelfand D, Sninsky J. Amplification and direct sequencing of fungal ribosomal RNA genes for phylogenetics. Pcr Protocols. 1990;31:315-22.

18. Camarero S, Ibarra D, Martínez MJ, Martínez AT. Lignin-derived compounds as efficient laccase mediators for decolorization of different types of recalcitrant dyes. Appl Environ Microbiol. 2005;71:1775-84.

19. Dhouib A, Hamza M, Zouari H, Mechichi T, H'midi R, Labat M, Martinez MJ, Sayadi S. Autochthonous fungal strains with high ligninolytic activities from Tunisian biotopes. Afr J. 2005;4:431-6.

20. Saleem M, Ali MS, Hussain S, Jabbar A, Ashraf M, Lee YS. Marine natural products of fungal origin. Nat Prod Rep. 2007;24:1142-52.

21. Rateb ME, Ebel R. Secondary metabolites of fungi from marine habitats. Nat Prod Rep. 2011:28:290-344

22. Zhang C, Kim S-K. Research and application of marine microbial enzymes: status and prospects. Mar Drugs. 2010;8:1920-34.

23. Newell SY. Established and potential impacts of eukaryotic mycelial decomposers in marine/terrestrial ecotones. J Exp Mar Biol Ecol. 1996;200: 187-206.

24. Shanuja SK, Iswarya S, Gnanamani A. Marine fungal DHICA as a UVB protectant: assessment under in vitro and in vivo conditions. J Photoch Photobio. 2018:179:139-48.

25. An CY, Li XM, Li CS, Wang MH, Xu GM, Wang B-G. Aniquinazolines A-D, four new quinazolinone alkaloids from marine-derived endophytic fungus Aspergillus nidulans. Mar Drugs. 2013;11:2682-94.

26. Xu J, Liu P, Li X, Gan L, Wang P. Novel Stemphol derivatives from a marine fungus Pleospora sp. Nat Prod Res. 2019;33:367-73.

27. Inderbitzin P, Kohlmeyer J, Volkmann-Kohlmeyer B. L Berbee M. Decorospora, a new genus for the marine ascomycete Pleospora gaudefroyi. Mycol. 2002;94:651-9.

28. Schoch CL, Seifert KA, Huhndorf S, Robert V, Spouge $J$, Levesque CA, et al. Nuclear ribosomal internal transcribed spacer (ITS) region as a universal DNA barcode marker for Fungi. Natl Acad Sci USA. 2012;109:6241-6.

29. Stielow JB, Lévesque CA, Seifert KA, Meyer W, Iriny L, Smits D, Renfurm R, GJM V, Groenewald M, Chaduli D, Lomascolo A, Welti S, Lesage-Meessen L, Favel A, AMS A-H, Damm U, Yilmaz N, Houbarken J, Lombard L, Quaedvlieg W, Binder M, LAI V, Vu D, Yurkov A, Begerow D, Roehl O, Guerreiro M, Fonseca A, Samerpitak K, Van Diepeningen AD, Dolatabadi S, LF MO, Casaregola S, Mallet S, Jacques N, Roscini L, Egidi E, Bizert C, GarciaHermoso D, Martin MP, Deng S, Groenewald JZ, Boekhout T, de Beer ZW, Barnes I, Duong TA, Wingfield MJ, de Hoog GS, Crous PW, Lewis CT, Hambleton S, Hambleton S, TAA M, Al-Zahrani HS, Almaghrabi OA, LouisSeize G, Assabgui R, Mccormick W, Omar G, Dukik K, Cardinali G, Eberhard $U$, de Vries M, Robert V. One fungus, which genes? Development and assessment of universal primers for potential secondary fungal DNA barcodes. Persoonia. 2015;35:242-63.

30. Wu Q, Sun R, Ni M, Yu J, Li Y, Yu C, Dou K, Ren J, Chen J. Identification of a novel fungus, Trichoderma asperellum GDFS1009, and comprehensive evaluation of its biocontrol efficacy. PLoS One. 2017;12:e0179957.

31. Shi ZZ, Fang ST, Miao FP, Yin XL, Ji NY. Trichocarotins A-H and trichocadinin $a$, nine sesquiterpenes from the marine-alga-epiphytic fungus Trichoderma virens. Bioorg Chem. 2018:81:319-25.

32. Pang $X$, Lin $X$, Tian $Y$, Liang $R$, Wang J, Yang B, Zhou $X$, Kaliyaperumal $K$, Luo $X$, Tu Z, Liu $Y$. Three new polyketides from the marine sponge-derived fungus Trichoderma sp. SCSIO41004. Nat Prod Res. 2017;32:105-11. 
33. Korkmaz MN, Ozdemir SC, Uzel A. Xylanase production from marine derived Trichoderma pleuroticola 08CK001 strain isolated from mediterranean coastal sediments. J Basic Microbiol. 2017;57:839-51.

34. Zhang L, Niaz SI, Wang Z, Zhu Y, Lin Y, Li J, Liu L. a-Glucosidase inhibitory and cytotoxic botryorhodines from mangrove endophytic fungus Trichoderma sp. 307. Nat Prod Res. 2018;32:2887-92.

35. Song YP, Miao FP, Fang ST, Yin XL, Ji NY. Halogenated and nonhalogenated metabolites from the marine-alga-endophytic fungus Trichoderma asperellum cf44-2. Mar Drugs. 2018;16:266-75.

36. Ren J, Yang Y, Liu D, Chen W, Proksch P, Shao B, Lin W. Sequential determination of new peptaibols asperelines G-Z12 produced by marinederived fungus Trichoderma asperellum using ultrahigh pressure liquid chromatography combined with electrospray-ionization tandem mass spectrometry. J Chromatogr A. 2013;1309:90-5.

37. Levasseur A, Saloheimo M, Navarro D, Andberg M, Pontarotti P, Kruus K, Record E. Exploring laccase-like multicopper oxidase genes from the ascomycete Trichoderma reesei: a functional, phylogenetic and evolutionary study. BMC Biochem. 2010;11:32-43.

38. Bagewadi ZK, Mulla SI, Ninnekar HZ. Purification and immobilization of laccase from Trichoderma harzianum strain HZN10 and its application in dye decolorization. Genet Eng Biotechnol. 2017;15:139-50.

39. Gochev VK, Krastanov Al. Isolation of laccase producing Trichoderma spp. Bulg J Agric Sci. 2007;13:171-6.

40. Zafra G, Moreno-Montaño A, Absalón ÁE, Cortés-Espinosa DV. Degradation of polycyclic aromatic hydrocarbons in soil by a tolerant strain of Trichoderma asperellum. Environ Sci Pollut Res. 2015;22:1034-42.

41. Saravanakumar K, Kathiresan K. Bioremoval of the synthetic dye malachite green by marine Trichoderma sp. SpringerPlus. 2014;3:631-43.

42. Raghukumar C. Marine fungal biotechnology: An ecological perspective. Fungal Divers. 2008:31:19-35.

43. Theerachat M, Guieysse D, Morel S, Remaud-Siméon M, Chulalaksananukul W. Laccases from marine organisms and their applications in the biodegradation of toxic and environmental pollutants: a review. Appl Biochem Biotech. 2019;187:583-611.

44. D'Souza DT, Tiwari R, Sah AK, Raghukumar C. Enhanced production of laccase by a marine fungus during treatment of colored effluents and synthetic dyes. Enzyme Microb Tech. 2006;38:504-11.

45. Wikee S, Hatton J, Turbé-Doan A, Mathieu Y, Daou M, Lomascolo A, Kumar A, Lumyong S, Sciara G, Faulds CB. Record E. Characterization and dye decolorization potential of two laccases from the marine-derived fungus Pestalotiopsis sp. Inter J Mol Sci. 2019;20:1864-84.

46. Paul S, Bag SK, Das S, Harvill ET, Dutta C. Molecular signature of hypersaline adaptation: insights from genome and proteome composition of halophilic prokaryotes. Genome Biol. 2008;9:R70-89.

47. Collins PJ, Dobson A. Regulation of laccase gene transcription in Trametes versicolor. Appl Environ Microbiol. 1997;63:3444-50

48. Domínguez A, Gómez J, Lorenzo M, Sanromán Á. Enhanced production of laccase activity by Trametes versicolor immobilized into alginate beads by the addition of different inducers. World J Microb Biot. 2007;23:367-73.

49. Palmieri G, Giardina P, Bianco C, Fontanella B, Sannia G. Copper induction of laccase isoenzymes in the ligninolytic fungus Pleurotus ostreatus. Appl Environ Microbiol. 2000;66:920-4.

50. Hao J, Song F, Huang F, Yang C, Zhang Z, Zheng Y, Tian X. Production of laccase by a newly isolated deuteromycete fungus Pestalotiopsis sp. and its decolorization of azo dye. J Ind Microbiol Biot. 2006;34:233-40.

51. Nakade K, Nakagawa Y, Yano A, Konno N, Sato T, Sakamoto Y. Effective induction of pblac1 laccase by copper ion in Polyporus brumalis ibrc05015. Fungal Biol. 2013;117:52-61.

52. Piscitelli A, Giardina P, Lettera V, Pezzella C, Sannia G, Faraco V. Induction and transcriptional regulation of laccases in fungi. Curr Genomics. 2011;12:104-12.

53. Galhaup C, Wagner H, Hinterstoisser B, Haltrich D. Increased production of laccase by the wood-degrading basidiomycete Trametes pubescens. Enzyme Microb Tech. 2002;30:529-36.

54. Kaal E, Field J, Joyce T. Increasing ligninolytic enzyme activities in several white-rot basidomycetes by nitrogen-sufficient media. Bioresour Technol. 1995:53:133-9.

55. Afreen S, Anwer R, Singh RK, Fatma T. Extracellular laccase production and its optimization from Arthrospira maxima catalyzed decolorization of synthetic dyes. Saudi J Biol Sci. 2018;25:1446-53.

56. Stolz A. Basic and applied aspects in the microbial degradation of azo dyes. Appl Microbiol Biotechnol. 2001;56:69-80.
57. Husain Q. Potential applications of the oxidoreductive enzymes in the decolorization and detoxification of textile and other synthetic dyes from polluted water: a review. Biotechnol. 2006;26:201-21.

58. Young L, Yu J. Ligninase-catalysed decolorization of synthetic dyes. Water Res. 1997;31:1187-93.

59. O'Neill C, Hawkes FR, Hawkes DL, Lourenço ND, Pinheiro HM, Delée W. Colour in textile effluents - sources, measurement, discharge consents and simulation: a review. J Chem Technol Biot. 1999;74:1009-18.

60. Bonugli-Santos RC, Durrant LR, da Silva M, Sette LD. Production of laccase manganese peroxidase and lignin peroxidase by Brazilian marine-derived fungi. Enzyme Microb Tech. 2010;46:32-7.

61. Abadulla E, Robra K-H, Gubitz GM, Silva LM, Cavaco-Paulo A. Enzymatic decolorization of textile dyeing effluents. Res J. 2000;70:409.

62. Levine WG. Metabolism of AZO dyes: implication for detoxication and activation. Drug Metab Reviews. 1991;23:253-309.

63. Forootanfar H, Moezzi A, Aghaie-Khozani M, Mahmoudjanlou Y, Ameri A, Niknejad F, Faramarzi M. Synthetic dye decolorization by three sources of fungal laccase. Iran J Environ Healt Sci Eng. 2012;9:27.

64. Mechichi T, Mhiri N, Sayadi S. Remazol brilliant blue R decolourization by the laccase from Trametes trogii. Chemosphere. 2006;64:998-1005.

65. Raghukumar C, D'Souza T, Thorn R, Reddy C. Lignin-modifying enzymes of flavodon flavus, a basidiomycete isolated from a coastal marine environment. Appl Environ Microbiol. 1999;65:2103-11.

66. Divya LM, Prasanth GK, Sadasivan C. Isolation of a salt tolerant laccase secreting strain of Trichoderma sp. NFCCl-2745 and optimization of culture conditions and assessing its effectiveness in treating saline phenolic effluents. J Environ Sci. 2013;25:2410-6.

67. Adnan LA, Sathishkumar P, Mohd Yusoff AR, Hadibarata T. Metabolites characterisation of laccase mediated reactive black 5 biodegradation by fast growing ascomycete fungus Trichoderma atroviride F03. Int Biodeterior Biodegradation. 2015;104:274-82.

68. Daâssi D, Zouari-Mechichi H, Frikha F, Martinez MJ, Nasri M, Mechichi T. Decolorization of the azo dye Acid Orange 51 by laccase produced in solid culture of a newly isolated Trametes trogii strain. 3 Biotech. 2013;3:115-25.

69. Plácido J, Chanagá X, Ortiz-Monsalve S, Yepes M, Mora A. Degradation and detoxification of synthetic dyes and textile industry effluents by newly isolated Leptosphaerulina sp. from Colombia. Bioresour Bioproc. 2016;5:40914

70. Saroj S, Kumar K, Pareek N, Prasad R, Singh RP. Biodegradation of azo dyes acid red 183, direct blue 15 and direct red 75 by the isolate Penicillium oxalicum SAR-3. Chemosphere. 2014;107:240-8.

71. Altschul SF, Madden TL, Schäffer AA, Zhang J, Zhang Z, Miller W, Lipman DJ. Gapped BLAST and PSI-BLAST: a new generation of protein database search programs. Nucleic Acids Res. 1997;25:3389-402.

72. Thompson JD, Higgins DG, Gibson TJ. CLUSTAL W: improving the sensitivity of progressive multiple sequence alignment through sequence weighting, position-specific gap penalties and weight matrix choice. Nucleic Acids Res. 1994;22:4673-80.

73. Kumar S, Stecher G, Li M, Knyaz C, Tamura K. MEGA X: Molecular evolutionary genetics analysis across computing platforms. Mol Biol Evol. 2018:35:1547-9.

74. Gascuel O. BIONJ: an improved version of the NJ algorithm based on a simple model of sequence data. Mol Biol Evol. 1997;14:685-95.

75. Zouari-Mechichi H, Mechichi T, Dhouib A, Sayadi S, Martínez AT, Martínez MJ. Laccase purification and characterization from Trametes trogii isolated in Tunisia: decolorization of textile dyes by the purified enzyme. Enzyme Microb Tech. 2006:39:141-8.

76. More SS, Renuka PS, Pruthvi K, Swetha M, Malini S, Veena SM. Isolation, purification, and characterization of fungal Laccase from Pleurotus sp. Enzyme Res. 2011;2011:1-7.

77. Mansur M, Arias ME, Copa-Patiño JL, Flärdh M, González AE. The white-rot fungus Pleurotus ostreatus secretes laccase isozymes with different substrate specificities. Mycologia. 2003;95:1013-20.

\section{Publisher's Note}

Springer Nature remains neutral with regard to jurisdictional claims in published maps and institutional affiliations. 